\title{
MATERIAIS VIVOS, O CASO DA CELULOSE BACTERIANA: REVISÃO BIBLIOGRÁFICA DA APLICAÇÃO NO DESIGN INDUSTRIAL, ARQUITETURA E MODA
}

\section{LIVING MATERIALS, THE CASE OF BACTERIAL CELLULOSE: A LITERATURE REVIEW OF APPLICATIONS IN INDUSTRIAL DESIGN, ARCHITECTURE AND FASHION}

ELISA STROBEL DO NASCIMENTO, M.SC. | UFPR

GISLAINE MARIA LAU |UFPR

FELIPE DE CARVALHO ISHIY | UFPR

ADRIANO HEEMANN, Dr. |UFPR

\begin{abstract}
RESUMO
O Design com materiais vivos, em que participam outros organismos na materialização dos artefatos, traz novas possibilidades e desafios teóricos e práticos. No recorte do design envolvendo bactérias, esta pesquisa tem como objetivo levantar e mapear as perspectivas e aplicações da celulose bacteriana no design industrial, arquitetura e moda. O procedimento metodológico é a revisão sistemática que resultou na análise de 27 trabalhos acadêmicos e 16 depósitos de patentes nacionais e internacionais. Como resultado sumarizam-se as aplicações relatadas e prospectadas. Os destaques estão nas aplicações têxteis e nos processos de cultivo, conformação e acabamentos. São relatadas as dificuldades e discutidas oportunidades para os designers com estes materiais.
\end{abstract}

PALAVRAS CHAVE: Biodesign; Materiais Vivos; Biofabricação; Celulose Bacteriana

\begin{abstract}
Design with living materials, when other organisms take part in the artifact's development and production, unveils new possibilities, theoretical and practical challenges. This research focuses on design with bacteria and aims to identify and map applications and perspectives for bacterial cellulose in industrial design, architecture and fashion. Through systematic literature review, we analyzed 27 academic works and 16 national and international patents. We found an emphasis on fashion and textile purposes and a focus on growing, molding and finishing processes. Finally, we present the difficulties for this material and discuss opportunities for designers.
\end{abstract}

KEY WORDS: Biodesign; Living Materials; Biofabrication; Bacterial Cellulose 


\section{INTRODUÇÃO}

O Biodesign, uma vertente que implica no trabalho do designer na intersecção com a biologia, tem sido cada vez mais referenciado e assume nomes como biofabricação e design com materiais vivos (NASCIMENTO; HEEMANN, 2020). Nesta prática outros seres vivos não-humanos participam na criação e materialização de artefatos. Exemplos seriam a produção de mobília pela indução de árvores cultivadas diretamente na forma projetada (FULL GROWN, 2020) e vasos e embalagens crescidos em moldes a partir de compósitos com fungos (RADIAL BIO, 2020). O conceito de material vivo parece ainda não ser consensual. Enquanto alguns autores mantém vivos os organismos nos artefatos para o uso, outros os "desativam" após a fabricação, como geralmente ocorre nos casos de produtos feitos com fungos (NASCIMENTO; HEEMANN, 2020). Além do argumento da sustentabilidade, haveriam possibilidades inerentes às funções relacionadas às "habilidades" de diversas espécies, como por exemplo, a proteção contra radiação (SHUNK; GOMEZ; AVERESCH, 2020). A variação de condições de nutrição e desenvolvimento destes organismos pelos designers, parece abrir um horizonte de possibilidades ainda mais amplo no que se refere ao uso dos materiais vivos (CAMERE; KARANA, 2018).

No presente trabalho explora-se o recorte do design com a participação de bactérias, especificamente a celulose bacteriana (CB). O objetivo é levantar e mapear as principais perspectivas e aplicações da CB no design industrial, na arquitetura e na moda. Esta é uma versão revisada e expandida do trabalho apresentado por Nascimento et al. (2021), que traz informações mais detaIhadas sobre cultivo, secagem, impermeabilização e acabamentos para aplicação da celulose bacteriana nestas áreas. A seguir, introduz-se o Design com bactérias, são então apresentados os procedimentos metodológicos e os resultados analisados, discutidos e organizados em categorias. Conclui-se com as possibilidades de estudos futuros para aplicação destes materiais.

\subsection{Design com materiais vivos: bactérias}

Exemplos de trabalhos de designers com bactérias variam do uso para pigmentação, até aplicação de tecnologias avançadas, como a impressão tridimensional em substrato com bactérias vivas, ilustradas na Figura 1.

Uma das formas mais usuais de bactérias em projetos de design é a biofabricação de artefatos de celulose bacteriana (CB). Esta recebe outros nomes como couro bacteriano, couro de kombucha, couro vegano, biofilme, biocelulose, celulose nativa, nanocelulose cristalina, mãe de vinagre (COSTA; BIZ, 2017; DAMSIN, 2019). A CB, sintetizada por bactérias, é um polímero natural renovável e biodegradável (RATHINAMOORTHY; KIRUBA, 2020). Algumas das propriedades da $C B$ são alta pureza em relação à celulose vegetal, alta cristalinidade, alta retenção de água, alta resistência à tensão de tração e estabilidade térmica (DERME; MITTERBERGER; DI TANNA, 2016; DOMSKIENE; SEDERAVICIUTE; SIMONAITYTE， 2019; NIYAZBEKOVA; NAGMETOVA; KURMANBAYEV, 2018). A Figura 2 apresenta exemplos de artefatos crescidos em CB.

$O$ processo de microbial weaving, demonstrado no calçado ao lado superior direito da Figura 2, envolve técnicas e equipamentos mais elaborados, como uso de tecnologias CNC (MODERN SYNTHESIS, 2020). Por outro lado, Camere e Karana (2018) e Damsin (2019) descrevem processos do tipo "faça-você-mesmo", apoiados em fóruns de compartilhamento de conhecimento e experimentos empíricos. Exemplos seriam a banqueta Xylium (HÜLSEN, 2011) e a Jaqueta de Suzanne Lee (TED, 2011) também ilustrados na Figura 2.

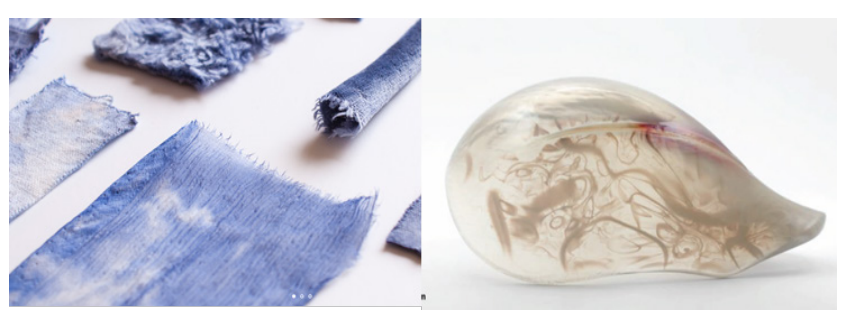

Figura 1: Exemplos de aplicação de design com bactérias

Fonte: da esquerda para a direita, Living Colour (2017, p.25); Smith et al. (2020, p.8).

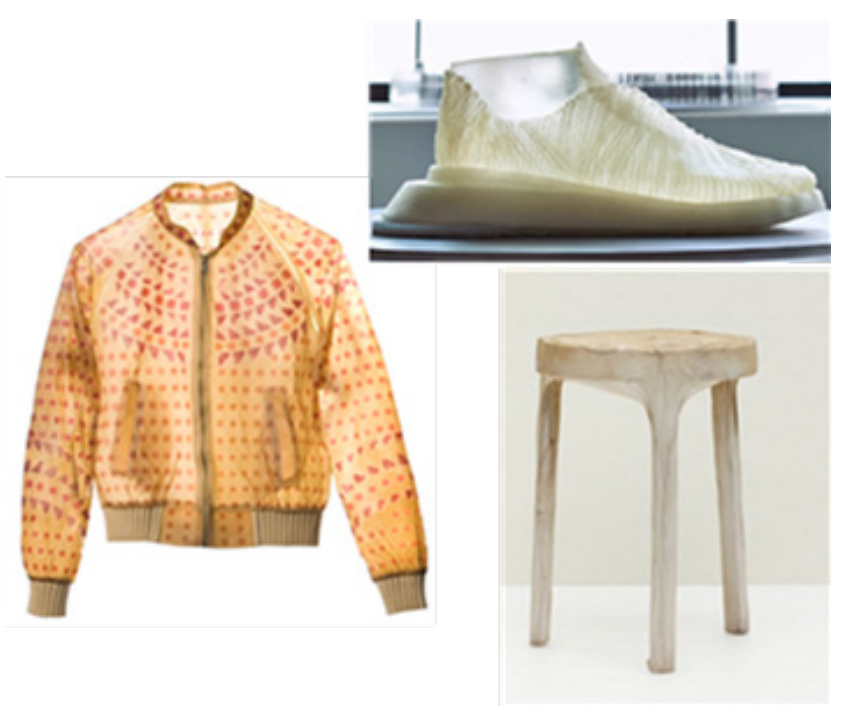

Figura 2 - Exemplos de aplicação de design com celulose bacteriana

Fonte: à esquerda TED (2011); à direita superior Modern Synthesis (2020); à direita inferior Hülsen (2011) 
Um método comum para a obtenção de CB parte da fermentação do caldo de chá de Kombucha. Seu subproduto denominado SCOBY (Symbiotic Culture of Bacteria and Yeast) é composto de celulose, bactérias, leveduras e água (NG, 2017). Segundo Zolotovsky (2012), a CB seca contém células bacterianas "desativadas", mas uma pequena fração delas permanece viva. Quando recolocadas em meio de cultivo, retomam as funções de crescimento, reprodução, etc., desempenhando inclusive reparação de fraturas no material. Por ser um material vivo, a CB traz oportunidades de estruturar a celulose de maneiras diferentes, pois os organismos respondem aos estímulos apresentados crescendo, se regenerando e biodegradando (ZOLOTOVSKY, 2012).

\section{PROCEDIMENTOS METODOLÓGICOS}

Para o levantamento da literatura adaptou-se o método da Revisão Bibliográfica Sistemática (RBS) apresentado por Conforto, Amaral e Silva (2011), em quatro etapas: (1) busca em bases de dados; (2) busca em ferramenta livre; (3) busca em bases de depósito de patentes e (4) categorização e análise dos dados.

Em uma primeira etapa, as bases de dados selecionadas foram a Web of Science (Thomson and Reuters) e Scopus (Elsevier). A string buscada na Scopus foi: "bacterial cellulose" AND "product design" OR "fashion" OR "architecture". Na base de dados Web of Science, as palavras que compõe a string foram combinadas em pares. Desta maneira, obtiveram-se 307 resultados. O recorte, na leitura do título e resumo, usou como filtro os seguintes critérios para exclusão da amostra:

(1) abordagem apenas das questões técnicas do material, ou construção e estrutura da célula, sem apresentação de possibilidades de aplicação construtiva em artefatos. Trabalhos que listaram possibilidades de aplicações do material com exemplos foram mantidos;

(2) aplicações restritas à tecidos de órgãos e curativos;

(3) aplicação restrita à nanogeradores, capacitores e eletrodos;

(4) aplicações restritas à recuperação de água ou solos.

Após a remoção de repetições e aplicação dos critérios de exclusão, foram obtidos 20 trabalhos pertinentes, dos quais 4 não se teve acesso.

Para uma segunda etapa, replicou-se a mesma string utilizada na base Scopus com a ferramenta de busca livre Google. Os resultados listados foram lidos com o objetivo de identificar trabalhos científicos. A ferramenta omitiu trabalhos repetidos, considerando 100 resultados relevantes. Os mesmos critérios de exclusão foram considerados na leitura, resultando na inclusão de 8 artigos e 3 dissertações de mestrado. Ao todo, compõem a amostra da análise desta pesquisa 27 trabalhos acadêmicos publicados entre os anos 2006 e 2020.

A terceira etapa, referente aos depósitos de patentes, exigiu buscas separadas por palavras-chave, adaptadas a partir da primeira busca. Inicialmente, na base do Instituto Nacional da Propriedade Industrial (INPI), os termos procurados foram "biofilme", "nanocelulose", "kombucha" e "membrana de celulose". No banco de dados de patentes da América Latina e Espanha (LATIPAT-ESPACENET), além destes termos, foram adicionados "nano celulose" e "nanocelulosa". Por fim, na base United States Patent and Trademark Office (USPTO), buscou-se por: "kombucha leather", "bacterial cellulose", "bacterial fabric", "nanocellulose" e "SCOBY". O levantamento gerou 1264 resultados. Optouse por critérios de inclusão, ao invés de exclusão na leitura de títulos e resumos. Estes foram:

(1) produção da CB (indicando aplicação);

(2) processo de conformação ou acabamento (indicando aplicação);

(3) aplicação.

Resultaram do filtro 16 depósitos de patentes.

Por fim, a quarta etapa, de análise e categorização, consistiu na leitura de todos os artigos completos e dos resumos das patentes, estabelecendo categorias de análise, que são descritas nas sessões seguintes.

\section{RESULTADOS E DISCUSSÃO}

Os resultados, análise e discussão são divididos em duas sessões: os trabalhos acadêmicos e os depósitos de patentes.

\subsection{Trabalhos acadêmicos}

A maior parte dos estudos da amostra trata de combinações das condições para o crescimento de CB. Há autores que não apresentam experimentos próprios, mas compilam existentes. Alguns dos artigos realizam experimentos sintetizando e melhorando o material para obter propriedades físicas e mecânicas desejadas (KAMIŃSKI; JAROSZ; GRUDZIEŃ, 2020; NIYAZBEKOVA; NAGMETOVA; KURMANBAYEV, 2018). Há ainda, a preocupação com a organização estrutural da celulose (URAKI, Y. et al., 2006; RAHMAN; NETRAVALI, 2016; ZOLOTOVSKY; 2012). Vários estudos partem da bebida kombucha, que envolve também a presença de fungos $(B L O C H$, 2019; COSTA; BIZ, 2017; DOMSKIENE; SEDERAVICIUTE; SIMONAITYTE, 2019; KAMINSKI et al., 2020; GARCÍA; PRIETO, 2019; MIHALEVA, 2020; NG, 2017; WOOD, 2019; RATHINAMOORTHY; KIRUBA, 2020). 
Sabe-se que o nome Komagataeibacter xylinus compreende as espécies conhecidas como Acetobacter xylinum e Gluconacetobacter xylinus. Estes foram os nomes das espécies mais mencionadas na amostra (14 artigos e 8 artigos, respectivamente). Outros 4 trabaIhos relatam a presença das espécies Agrobacterium, Achromobacter, Rhodobacter, Komagataeibacter, Bacterium gluconicum, Gluconacetobacter sucrofermentans. Fungos são relatados em 2 casos como comuns em simbiose: Zygosaccharomyces bailii, Zygosaccharomyces kombuchensis, Pichia fluxum e Saccharomyces sp., entre outros. O tempo de cultivo varia de 4 a 30 dias na amostra, o intervalo mais recorrente é de 10 a 14 dias e 6 a 7 dias, ambos em 7 artigos.

A preocupação da produção em escala é encontrada em diversos autores (DERME; MITTERBERGER; DI TANNA, 2016; DAMSIN, 2019; DOMSKIENE; SEDERAVICIUTE; SIMONAITYTE, 2019; RATHINAMOORTHY; KIRUBA, 2020; NIYAZBEKOVA; NAGMETOVA; KURMANBAYEV, 2018; VELÁSQUEZRIAÑO; BOJACÁ, 2017). A Tabela 1 sumariza a distribuição de aplicações descritas na amostra.

\begin{tabular}{|l|l|}
\hline Aplicações da CB na amostra & Frequência N=27 (100\%) \\
\hline Têxtil, moda, vestuário & $18(67 \%)$ \\
\hline Calçados & $3(11 \%)$ \\
\hline Vestíveis joias e acessórios & $8(30 \%)$ \\
\hline Arquitetura & $5(19 \%)$ \\
\hline Mobiliário & $3(11 \%)$ \\
\hline Utensílios domésticos & $1(4 \%)$ \\
\hline Objetos decorativos/artísticos & $4(15 \%)$ \\
\hline Embalagens & $4(15 \%)^{*}$ \\
\hline $\begin{array}{l}\text { Materiais engenheirados / Materiais } \\
\text { vivos engenheirados/ compósitos }\end{array}$ & $4(15 \%)$ \\
\hline Alternativa ao couro & $3(11 \%)$ \\
\hline Alternativa aos polímeros em geral & $1(4 \%)$ \\
\hline $\begin{array}{l}\text { Alternativa para indústria de papéis, } \\
\text { ou melhoramento de papéis }\end{array}$ & $7(26 \%)$ \\
\hline Indústria automotiva & $1(4 \%)$ \\
\hline $\begin{array}{l}\text { Outros (aplicações médicas, indústria } \\
\text { de cosméticos, alimentícia, meio } \\
\text { ambiente, eletrônica e audiovisual) }\end{array}$ & $10(37 \%)$ \\
\hline
\end{tabular}

*Valores aqui corrigidos em relação ao apresentado em Nascimento et al. (2021)

Tabela 01: Distribuição das aplicações na amostra.

Fonte: Elaborado pelos autores.

Dos autores que discriminam a aplicação em detalhes (não apenas mencionando uma segmentação): em têxteis e vestuário, Costa e Biz (2017) exemplificam uma luva e uma jaqueta; Kaminski et al. (2020) apresentam uma camiseta com aplicações em CB. Na categoria de vestíveis, joias e acessórios, Kaminski et al. (2020) desenvolvem braceletes e $\mathrm{Ng}$ (2017) apresenta um vestível com LEDs internos para uso no pescoço, ombro e braços. Em aplicações arquitetônicas, discriminam-se materiais acústicos de alto desempenho (ZOLOTOVSKY; GAZIT; ORTIZ, 2018) e estudos para estruturas tênseis (DAMSIN, 2019). Costa e Biz (2017) listam ainda exemplos de tigela, luminária e capa de celular, que foram categorizados como utensílios domésticos. A comparação com o couro é destacada por Yim, Song e Kim (2017). Os autores sugerem que a resistência à tensão de tração da $\mathrm{CB}$ seria duas vezes superior ao couro de flor superior. Segundo os mesmos autores, ambos os materiais teriam espessura e aparência similares. García e Prieto (2019) também reforçam a similaridade do couro e da $\mathrm{CB}$ em relação à maciez e elasticidade, com a vantagem da possibilidade de cultivo com extremidades retas e uniformes, e com menor variação de qualidade. Na categoria materiais engenheirados (termo reproduzido conforme descrito pelos autores), destacam-se o desenvolvimento com padrão de favo (URAKI, Y. et al., 2006) e os materiais em que as bactérias continuam vivas, apresentando propriedades como a de fluorescência, entre outras (CAROASTORGA; WALKER; ELLIS, 2020). Na categoria melhoramento de papéis, que se estende também para as embalagens, a busca por propriedades de barreira a partir da $\mathrm{CB}$, como impermeabilidade ao ar, água, vapores, gorduras e microorganismos, é estudada por Fillat et al. (2018). Finalmente, na categoria outros, destaca-se a aplicação da translucidez da CB para tecnologias OLED (LEGNANI et al., 2019). É importante discriminar que Costa e Biz (2017) e Rathinamoorthy e Kiruba (2020) fazem trabalhos de revisão bibliográfica, sumarizando aplicações no segmento da moda.

A Tabela 2 sintetiza a distribuição dos principais processos descritos na amostra.

\begin{tabular}{|l|l|}
\hline Processos descritos na amostra & Frequência N=27 (100\%) \\
\hline Cultivo plano da película & $4(15 \%)$ \\
\hline Cultivo estático & $6(22 \%)$ \\
\hline Cultivo estático e plano da película & $6(22 \%)$ \\
\hline Cultivo com agitamento & $3(11 \%)$ \\
\hline $\begin{array}{l}\text { Cultivo estático com envolvimen- } \\
\text { to de fibras ou outras estruturas } \\
\text { (permanentes ou degradáveis) }\end{array}$ & $6(22 \%)$ \\
\hline $\begin{array}{l}\text { Cultivo estático sobre molde } \\
\text { 3D imerso em substrato }\end{array}$ & $6(22 \%)$ \\
\hline Secagem sobre molde 3D & $4(15 \%)$ \\
\hline $\begin{array}{l}\text { Conformação com molde tridimensio- } \\
\text { nal, sem especificação do tipo de molde }\end{array}$ & $5(19 \%)$ \\
\hline Congelamento antes da secagem & $2(7 \%)$ \\
\hline
\end{tabular}




\begin{tabular}{|l|l|}
\hline Secagem à temperatura ambiente & $1(4 \%)^{*}$ \\
\hline Secagem em outras temperaturas & $5(19 \%)$ \\
\hline Pigmentação em meio de cultivo & $2(7 \%)$ \\
\hline Pigmentação pós cultivo & $2(7 \%)$ \\
\hline $\begin{array}{l}\text { Lavagem com água e sabão, } \\
\text { água destilada ou outros }\end{array}$ & $5(19 \%)$ \\
\hline $\begin{array}{l}\text { Purificação com soda cáus- } \\
\text { tica e água sanitária }\end{array}$ & $1(4 \%)$ \\
\hline $\begin{array}{l}\text { Tratamento com glicerol, óleos, ceras, } \\
\text { ácido nítrico, etileno glicol, cloreto de } \\
\text { etilenoglicol cloro, NaOH, ácido esteárico }\end{array}$ & $6(22 \%)$ \\
\hline Impressão 3D (biológica) & $3(11 \%)$ \\
\hline Corte e costura & $4(15 \%)$ \\
\hline Autocolagem & $5(19 \%)$ \\
\hline Outros & $14(52 \%)$ \\
\hline
\end{tabular}

*Valores aqui inclusos, faltantes em relação ao apresentado em Nascimento et al. (2021)

Tabela 02: Distribuição dos processos descritos na amostra.

Fonte: Elaborado pelos autores.

Zolotovsky (2012) relata que o aspecto principal do design com sistemas vivos é o planejamento e controle das condições de cultivo, induzindo o comportamento do organismo. A autora descreve as seguintes variáveis/parâmetros: nutrientes; oxigenação; temperatura; $\mathrm{Ph}$; e tempo (em função das condições anteriores). São comuns as variações e mutações espontâneas do organismo, o que exige "um diálogo constante entre o designer e o artífice" (ZOLOTOVSKY, 2012).

Com relação ao cultivo, Bloch (2019) experimenta que amostras sem acesso à luz solar se desenvolvem mais espessas. Todos os utensílios que entram em contato durante o cultivo da $\mathrm{CB}$, como recipientes e misturadores, precisam ser esterilizados para evitar o surgimento de organismos concorrentes (DAMSIN, 2019). Costa e Biz (2017) recomendam substituir $75 \%$ do substrato durante o desenvolvimento da $\mathrm{CB}$, a fim de evitar a formação de boIhas de gás carbônico que surgem durante a fermentação. Estas bolhas influenciariam na regularidade da superfície da CB e podem estar associadas ao excesso de açúcar, ou a uma população grande de organismos na cultura. Quanto a esta dificuldade, Rathinamoorthy e Kiruba (2020) explicam que o cultivo em meio agitado seria uma opção de oferecer mais oxigênio aos organismos. Velásquez-Riaño e Bojacá (2017) revisam a literatura sobre a produção de celulose bacteriana em diversos substratos. Os autores reportam o cultivo em substratos tipo melaços e xaropes a partir da fermentação de subprodutos da fabricação de sucos, extratos e biomassa vegetal. $\mathrm{O}$ uso de subprodutos sugere que a CB seja um material de custo mais acessível, segundo os autores. Harmon, Fairbourn e Thibault, (2020) testam 6 substratos e relatam que obtiveram o biofilme com melhor desempenho em cultivo de manitol de melaço seco ao ar. Os parâmetros de desempenho seriam a força de ruptura e ciclos de abrasão.

As dimensões das amostras cultivadas nos estudos variam. A maior amostra de CB neste levantamento bibliográfico é de $\mathrm{Ng}$ (2017), medindo $550 \mathrm{~mm} \times 1200 \mathrm{~mm}$ (largura $\mathrm{x}$ comprimento); e a menor é de Legnani et al., (2019), medindo $50 \mathrm{~mm} \times 6 \mathrm{~mm}$ (largura x comprimento). Quanto à espessura, os autores relatam reduções consideráveis durante a secagem. Bloch (2019) escreve que as amostras antes da secagem mediram entre 10 e $19 \mathrm{~mm}$, e depois de secas, passaram a medir aproximadamente 1 mm. Costa e Biz (2017) também descrevem uma redução similar: 10,5 mm antes da amostra seca e 0,9 mm depois de seca. As amostras mais finas nesta pesquisa são de Uraki et al. (2006), de $1.3 \mu \mathrm{m}$, e de Fillat et al. (2018), de 9,3 a $154 \mu \mathrm{m}$. A amostra mais espessa encontrada na revisão é descrita por Legnani et al. (2019), com $5 \mathrm{~mm}$.

Dos processos categorizados como "outros": Bloch (2019) experimenta a adição diária de substrato sobre uma estrutura de fios. Derme, Mitterberger e Di Tanna (2016) chamam de "processo de adesão" o cultivo estático e anaeróbico em recipiente de látex, que causa a inversão no metabolismo das bactérias. Estas assumiram a forma do recipiente, ao invés da formação na superfície. Os mesmos autores ainda sugerem processos de solidificação por calcificação da CB. Caro-Astorga, Walker e Ellis (2020) propõem cultivo em meio agitado para formação de estruturas esferoides de $\mathrm{CB}$, que se tornam módulos. Estes seriam então dispostos manualmente com uma pipeta na forma da estrutura 3D desejada. Por fim, os módulos são conectados pelo crescimento do biofilme. Damsin (2019) experimenta a prensa à quente para secagem e impermeabilização, com aditivos. Domskiene, Sederaviciute e Simonaityte (2019) sugerem a compressão do biofilme de CB para remoção de água. Kaminski et al. (2020) aplicam a CB sobre tecidos. Fillat et al. (2018) fazem o cultivo na superfície de filtro ou folhas de papel, e experimentam também camadas duplas revestidas com CB. Ng (2017) demonstra a prensagem em um molde rígido bipartido cortado a laser, que simula um padrão de dobras de origami. Ng e Wang (2016) apresentam um experimento em que um manequim (molde) é parcialmente mergulhado no substrato e rotacionado periodicamente. Uraki et al. (2006) realizam a secagem a vácuo, enquanto Zolotovski (2012) utiliza a liofilização para manutenção de formas 3D. A mesma autora idealiza um processo de "Impressão 3D biológica", em que o substrato é adicionado à medida que as camadas de CB 
são formadas, ou com a apresentação de estímulos, como raios UV. Por fim, Zolotovsky, Gazit e Ortiz (2018) propõem um cultivo parametrizado em moldes de silicone com condução do crescimento por fluxos e condições controladas por canais. Rathinamoorthy e Kiruba (2020) sumarizam informações a partir da revisão bibliográfica e descrevem um sistema de construção por bloqueadores de oxigênio. Estes seriam as formas "negativas" da forma desejada, que cresceria apenas onde haveria acesso ao oxigênio.

Com relação aos acabamentos, as cores mais relatadas da CB na amostra são tons de marrom e bege, em 10 artigos. Outras cores são possíveis com a adição de frutas e corantes, descritas em 4 artigos. Texturas diferentes são alcançadas dependendo dos processos de cultivo, aditivos e conformação (COSTA; BIZ, 2017; DERME; MITTERBERGER; DI TANNA, 2016). Bloch (2019) apresenta CB em rosa, roxo, vermelho, preto, branco e amarelo aplicados no meio de cultivo, sendo que as partes mais espessas do crescimento são menos pigmentadas. Mihaleva (2020) também desenvolve amostras em verde e rosa, além do marrom e do bege. $\mathrm{Ng}$ (2017) apresenta o uso de azul natural de Gardenia crassicaulis, vermelho a partir de corante alimentar, e corante natural de rosa rugosa. Alguns autores descrevem processos de clareamento com limpeza alcalina (DAMSIN, 2019), purificação com soda cáustica e água sanitária (COSTA; BIZ, 2017).

Para a produção de compósitos, alguns métodos já foram descritos anteriormente nos processos caracterizados como "outros". Costa e Biz (2017), a partir de revisão da literatura, explicam que os materiais de reforço podem ser incluídos durante o cultivo, ou impregnados em tratamentos pós cultivo. Derme, Mitterberger e Di Tanna (2016) sugerem estudos futuros para testes com o objetivo de formar compósitos estruturais com quitosana, hidroxiapatita, ou com agentes calcificantes de membranas 3D.

Técnicas impermeabilizantes envolvem o uso de óleos secativos e ceras naturais (COSTA; BIZ, 2017). Mihaleva (2020) relata um tratamento superficial com óleos para melhorar a impermeabilidade do material. Para comparar propriedades de absorção de água, Damsin (2019) reporta o resultado de um teste de imersão das amostras na água por $48 \mathrm{~h}$. Após o período de imersão, as amostras são pesadas para verificar a massa de água absorvida. Segundo o autor, uma amostra seca naturalmente e sem nenhum tratamento passou de $0,05 \mathrm{~g}$ para 0,011 g. Comparativamente, uma amostra tratada com óleo de coco e cera de abelha passou de $0,09 \mathrm{~g}$ para $0,014 \mathrm{~g}$. Para avaliar as propriedades de barreira da celulose bacteriana, Domskiene, Sederaviciute e Simonaityte (2019) analisaram a transmissão de vapor de água de acordo com a ISO 11092 e obtiveram resultado de 2,775-3,050 g/ m2 em 24 h. Fillat et al. (2018) também analisaram propriedades de barreira de papéis melhorados com celulose bacteriana. Eles relatam que resultados com bactérias $K$. xylinus obtém propriedades mais resistentes à absorção da água do que bactérias $G$. sucrofermentans, possivelmente pela produção de fibras mais longas por aquela espécie. Os autores obtém filtros menos permeáveis com a aplicação de celulose bacteriana em relação a filtros controle, especialmente quando estes compósitos de filtro e celulose bacteriana são secos em altas temperaturas. Kaminski et al. (2020) incluem testes com selamento por ácido esteárico, mas não encontram eficácia contra absorção de água para este tratamento.

Óleos e glicerol são descritos em acabamentos para melhorar condições de flexibilidade e maciez do material, consequentemente evitando um resultado quebradiço (DAMSIN, 2019; KAMINSKI et al., 2020; MIHALEVA, 2020). Damsin (2019) testa embeber o material em glicerol, com óleo de coco, cera de abelha, solução de ácido cítrico, etileno glicol e cloreto de etilenoglicol cloro (EGCC). $\mathrm{O}$ autor ainda desenvolve testes com material embebido em etil cianocrilato diluído com tolueno, ácido tânico e combinação de EGCC com prensa quente.

Diversas formas de secagem são descritas. Damsin (2019) explica que encontrou o melhor resultado de resistência em suas amostras quando secou o biofilme na prensa. $\mathrm{O}$ autor também propõe secagem sobre outros tecidos que absorvem água. Domskiene, Sederaviciute e Simonaityte (2019) encontram em seu estudo as melhores propriedades de deformação retidas com o tempo quando o material é seco a temperatura de $25^{\circ} \mathrm{C}$, em oposição a $50^{\circ} \mathrm{Ce} 75^{\circ} \mathrm{C}$. Os autores mantiveram as amostras nestas temperaturas até que mantivessem peso constante, indicando a secagem. Fillat et al. (2018) destacam a importância das condições de secagem no impacto dos resultados de impermeabilização de compósitos de papel e CB. Dos autores que propuseram congelamento antes da secagem, Derme, Mitterberger e Di Tanna (2016) registram que o congelamento durou 4 horas, seguido de secagem por 4 dias a $10^{\circ} \mathrm{C}$. Já Kaminski et al. (2020) submetem a amostra a 121 oC após o congelamento. O processo de liofilização já mencionado e utilizado por Zolotovski (2012) também envolve congelamento para remover a água por sublimação.

Damsin (2019) revisa a literatura em busca de informações sobre a tensão de tração da CB e encontra uma variação de 50 a $250 \mathrm{MPa}$. O autor estuda a tensão de ruptura 
para estruturas tênseis e encontra o valor de 91,89 MPa em uma de suas amostras tratadas com Etilenoglicol. Domskiene, Sederaviciute e Simonaityte (2019) relatam que a tensão de tração reduz com o passar do tempo. Em seu experimento voltado para aplicação na indústria da moda, os autores estimam a tensão de tração em 57 MPa na CB após 10 dias seca, com a redução para $46 \mathrm{MPa}$ após 30 dias seca. Harmon, Fairbourn e Thibault (2020) também investigam aplicações da $C B$ na indumentária e relatam na literatura valores de até $256 \mathrm{MPa}$, o que segundo os autores, seria comparável a alguns tecidos. Os autores testam diversos substratos de cultivo e encontram a melhor média de tensão de ruptura com amostras cultivadas com melado de cana e manitol, secas com congelamento entre -32 a -42 Fahrenheit: 11,75 N. Huang et al. (2013) reportam da literatura uma variação de 200 a 300 MPa na tensão de tração da CB. Yim, Song e Kim (2017) experimentam a CB para o desenvolvimento de tecidos sustentáveis, os autores encontraram o valor de tensão de tração de $177,6 \pm 8,88 \mathrm{~N} / \mathrm{mm}^{2}$.

Da consideração da viabilidade de aplicação, especialmente em produtos têxteis, autores divergem nas conclusões. Há os que defendem ainda haver um longo caminho de desenvolvimento (DOMSKIENE; SEDERAVICIUTE; SIMONAITYTE, 2019; HARMON; FAIRBOURN; THIBAULT, 2020). Em contraponto, há autores com perspectivas mais otimistas em relação à maturidade do desenvolvimento do material (KAMINSKI et al., 2020; NG; WANG, 2015). Domskiene, Sederaviciute e Simonaityte (2019) descrevem que as propriedades mudam significativamente com o tempo, a CB perde a elasticidade e a resistência de tensão à tração, e seria assim, improvável que este material seja durável. Rathinamoorthy e Kiruba (2020) citam um estudo com 33 participantes em que o material de CB teria sido aceito para acessórios vestíveis de moda (como joias), mas não para vestimentas. García e Prieto (2019) consideram que as propriedades hidrofílicas podem ser úteis em diversas aplicações, porém não são adequadas para a indústria calçadista.

Por fim, as publicações acadêmicas analisadas apresentam sugestões para estudos futuros. Por exemplo, é recomendado conhecer mais a fundo as possibilidades de trabalhabilidade do material (ZOLOTOVSKY, 2012; NG; WANG, 2015; YIM; SONG; KIM, 2017; DERME; MITTERBERGER; DI TANNA, 2016). São destacados os desafios na melhoria da impermeabilização e durabilidade, assim como a manutenção da flexibilidade do material durante o tempo (CAMERE; KARANA, 2018;DAMSIN, 2019; DOMSKIENE; SEDERAVICIUTE; SIMONAITYTE, 2019; KAMINSKI et al., 2020). Ainda, sugere-se como imprescindível o acompanhamento das práticas "faça-você-mesmo" de pesquisadores e laboratórios independentes, de artistas, de comunidades online, como o Biofabforum.org, que possuem uma produção expressiva em CB e materiais vivos em geral (CAMERE; KARANA, 2018; DAMSIN, 2019).

\subsection{Depósitos de patentes}

O Quadro 1 apresenta a relação dos depósitos de patentes analisados, as bases de dados, acompanhadas das palavras-chave de busca, o título e seu código, a categorização de seu objeto (produto, processo, suporte) e a provável aplicação. A maior parte dos resultados se refere a processos produtivos. Destes, 9 tratam do processo de cultivo, 3 explicitam processo de secagem, 3 tratam da patente de um suporte de cultivo, 1 trata do processo de conformação e 2 tratam do processo de acabamento. Dos resultados, 2 tratam da escala para uma produção industrial. A maior parte das patentes não especifica a aplicação do material resultante, 5 explicitam aplicações médicas e 3 especificam produtos têxteis, de vestuário, ou moda.

\begin{tabular}{|c|c|c|}
\hline Base/palavra chave & Título da patente (original)/código & Objeto/aplicação \\
\hline $\begin{array}{l}\text { USPTO } \\
\text { Bacterial fabric }\end{array}$ & $\begin{array}{l}\text { Process of preparing a dyed fabric including a bacterial biopolymer and } \\
\text { having unique appearance }-10.294 .611\end{array}$ & $\begin{array}{l}\text { Processo de acabamento para obtenção de } \\
\text { efeito "desgastado"; } \\
\text { Têxtil artigos de vestuário; }\end{array}$ \\
\hline $\begin{array}{l}\text { USPTO } \\
\text { Bacterial cellulose }\end{array}$ & $\begin{array}{l}\text { Method for producing a storable molded body made of bacterial cellulose } \\
-10.709 .820\end{array}$ & $\begin{array}{l}\text { Processo de conformação de corpos } \\
\text { moldados; } \\
\text { Processo de secagem; } \\
\text { Corpos moldados; }\end{array}$ \\
\hline $\begin{array}{l}\text { LATIPAT } \\
\text { Biopelicula }\end{array}$ & $\begin{array}{l}\text { Protocolo para la formacion de biopeliculas naturales simuladas - } \\
\text { ES19990906994T 19990212 }\end{array}$ & $\begin{array}{l}\text { Processo de cultivo; } \\
\text { (Sem menção de aplicação); }\end{array}$ \\
\hline $\begin{array}{l}\text { LATIPAT } \\
\text { Membrana de celulose }\end{array}$ & $\begin{array}{l}\text { Processo de obtenção de membrana de celulose bacteriana purifica- } \\
\text { da para uso na duraplastia craniana e espinhal e como substituto de } \\
\text { disco intervertebral - BR20161024479 } 20161020\end{array}$ & $\begin{array}{l}\text { Processo de cultivo; } \\
\text { Medicina; }\end{array}$ \\
\hline $\begin{array}{l}\text { USPTO } \\
\text { Bacterial cellulose }\end{array}$ & $\begin{array}{l}\text { Process for the preparation of cellulose film, cellulose film produced there- } \\
\text { by, artificial skin graft and its use - } 4.912 .049\end{array}$ & $\begin{array}{l}\text { Processo de cultivo; } \\
\text { Medicina, membrana separadora, couro } \\
\text { artificial; }\end{array}$ \\
\hline
\end{tabular}




\begin{tabular}{|c|c|c|}
\hline $\begin{array}{l}\text { INPI } \\
\text { Biofilme } \\
\text { INPI } \\
\text { Nanocelulose }\end{array}$ & $\begin{array}{l}\text { Método para controlar o crescimento de micro-organismos e/ou bio- } \\
\text { filmes em um processo industrial - BR } 1120200033170 \text { A2 }\end{array}$ & $\begin{array}{l}\text { Processo de cultivo; } \\
\text { (Sem menção de aplicação); }\end{array}$ \\
\hline $\begin{array}{l}\text { USPTO } \\
\text { Bacterial cellulose }\end{array}$ & $\begin{array}{l}\text { Nonwoven fabric-like product using a bacterial cellulose binder and me- } \\
\text { thod for its preparation - } 4.919 .753\end{array}$ & $\begin{array}{l}\text { Processo de cultivo como aglutinante; } \\
\text { Tecidos-não-tecidos; }\end{array}$ \\
\hline $\begin{array}{l}\text { LATIPAT } \\
\text { Nano Celulose }\end{array}$ & $\begin{array}{l}\text { Processo de produção em escala de filmes de celulose bacteriana puri- } \\
\text { ficada - BR20151017614 } 20150723\end{array}$ & $\begin{array}{l}\text { Processo de cultivo em escala (industrial); } \\
\text { Medicina, farmacotécnica e cosmiatria; }\end{array}$ \\
\hline $\begin{array}{l}\text { INPI } \\
\text { Membrana de celulose }\end{array}$ & $\begin{array}{l}\text { Processo para obtenção de manta e de membrana celulósica, proces- } \\
\text { so para obtenção de manta celulósica que incorpora outros materiais, } \\
\text { meio de cultura utilizado, bandejas fechadas de fermentação, equipa- } \\
\text { mento de secagem utilizado, membrana celulósica obtida por tal pro- } \\
\text { cesso e usos de ditas mantas e membranas - PI 0205499-0 A2 }\end{array}$ & $\begin{array}{l}\text { Processo de cultivo em escala (industrial); } \\
\text { Processo de acabamento (branqueamento); } \\
\text { Possibilita materiais compostos; } \\
\text { Compósitos; }\end{array}$ \\
\hline $\begin{array}{l}\text { LATIPAT } \\
\text { Membrana de celulose }\end{array}$ & $\begin{array}{l}\text { Celulose nanofibrilar, método para a fabricação de celulose na- } \\
\text { nofibrilar, membrana, uso de celulose nanofibrilar, e, produto - } \\
\text { BR20171123567 } 20150504\end{array}$ & $\begin{array}{l}\text { Processo de cultivo, } \\
\text { Produto; } \\
\text { Celulose nanofibrilar; }\end{array}$ \\
\hline $\begin{array}{l}\text { USPTO } \\
\text { Kombucha leather }\end{array}$ & $\begin{array}{l}\text { Isolated bacterial strain of gluconacetobacter oboediens and an opti- } \\
\text { mized economic process for microbial cellulose production therefrom } \\
-10.053 .718\end{array}$ & $\begin{array}{l}\text { Processo de cultivo; } \\
\text { Processo de secagem; } \\
\text { Medicina; }\end{array}$ \\
\hline $\begin{array}{l}\text { INPI } \\
\text { Membrana de celulose }\end{array}$ & $\begin{array}{l}\text { Processo de secagem de membranas de celulose microbiana para uso } \\
\text { médico }\end{array}$ & $\begin{array}{l}\text { Processo de secagem; } \\
\text { Medicina; }\end{array}$ \\
\hline $\begin{array}{l}\text { INPI } \\
\text { Kombucha }\end{array}$ & $\begin{array}{l}\text { Aplicativo, movido por painéis fotovoltaicos orgânicos, com sola e al- } \\
\text { ças revestidas em kombucha - BR } 1020170164144 \text { A2 }\end{array}$ & $\begin{array}{l}\text { Produto; } \\
\text { Calçado; }\end{array}$ \\
\hline $\begin{array}{l}\text { LATIPAT } \\
\text { Biofilme }\end{array}$ & Dispositivo de crescimento de biofilme - BR20010112921 20010712 & $\begin{array}{l}\text { Suporte para cultivo; } \\
\text { (Sem menção de aplicação); }\end{array}$ \\
\hline $\begin{array}{l}\text { LATIPAT } \\
\text { Biopelicula }\end{array}$ & $\begin{array}{l}\text { Soporte para crecimiento de mycobacterium smegmatis } \\
\text { MX20180006342 } 20180503\end{array}$ & $\begin{array}{l}\text { Suporte para cultivo; } \\
\text { (Sem menção de aplicação); }\end{array}$ \\
\hline $\begin{array}{l}\text { USPTO } \\
\text { Nanocellulose }\end{array}$ & Nanocellulose surface coated support material - 9.506.186 & $\begin{array}{l}\text { Suporte para cultivo; } \\
\text { (Sem menção de aplicação); }\end{array}$ \\
\hline
\end{tabular}

Quadro 01: Depósitos de patente, seus objetos e aplicações citadas. Fonte: autores.

Observa-se uma ênfase nos processos produtivos envolvendo a $C B$ tanto nos trabalhos acadêmicos quanto nos depósitos de patentes.

\section{CONCLUSÃO}

O presente artigo apresenta um levantamento e mapeamento das principais perspectivas e aplicações da CB no design industrial, na arquitetura e na moda. Trata-se da versão revisada e expandida do trabalho apresentado por Nascimento et al. (2021), que inclui informações mais detalhadas sobre cultivo, secagem, impermeabilização e acabamentos para aplicação da celulose bacteriana nestas áreas. Este é um recorte do projeto com bactérias nos materiais vivos. O procedimento metodológico é a revisão bibliográfica sistemática com a busca de trabalhos acadêmicos em bases de dados e em bases de registros de patentes, que possibilitou a análise de 27 trabalhos acadêmicos e 16 registros de patentes.

As aplicações têxteis e de moda compõe a maior parte da amostra. Observa-se a ênfase nos processos de produção e conformação da CB, embora ainda haja divergências quanto a sua aplicação sem maiores desenvolvimentos.
Os principais desafios para este material se referem à impermeabilização, ao desenvolvimento de técnicas para trabalhá-lo (processos) e à busca pelo aumento de sua durabilidade. É relevante a proposta de novas aplicações que valorizem as características da $\mathrm{CB}$, o que é oportunidade para o campo do design. Como exemplo, a exploração de métodos como o Material Driven Design (KARANA et al., 2018), que pressupõe a experiência do usuário e as características do material para desenvolver aplicações que aproveitem as qualidades existentes do material.

Para trabalhos futuros, recomenda-se o acompanhamento de iniciativas não acadêmicas, por exemplo, a partir de comunidades na internet, artistas, pesquisadores e laboratórios independentes. Do mesmo modo, sugere-se complementar a busca de patentes com a base de dados European Patent Office (EPO). Poderiam ser também investigadas possíveis aplicações de outras espécies de bactérias, os materiais vivos engenheirados e outras formas de cultivo das bactérias no design industrial, na arquitetura e na moda. Por fim, sugere-se a pesquisa sobre diferentes técnicas de crescimento, sobre o uso de diferentes suportes e substratos. 


\section{REFERÊNCIAS}

BLOCH, C. Design Potential of Microbial Cellulose in Growing Architecture. 2019. 91p. Dissertação - Chalmers School of Architecture. Department of Architecture and Civil Engineering. Göteborg, 2019.

CAMERE, S.; KARANA, E. Fabricating materials from living organisms: An emerging design practice. Journal of Cleaner Production, v. 186, p. 570-584, 2018.

CAMERE, S.; KARANA, E. Growing materials for pro-duct design. Alive. Active. Adaptive: International Conference on Experiential Knowledge and Emerging Materials, EKSIG 2017, Delft. Anais... Delft, 2017. p.101-115.

CARO-ASTORGA, J.; WALKER, K.; ELLIS, T. Bacterial cellulose spheroids as building blocks for $2 \mathrm{D}$ and $3 \mathrm{D}$ engineered living materials. bioRxiv, 2020. doi: https://doi.org/10.1101/2020.05.11.0881382020.

CONFORTO, E. C.; AMARAL, D. C.; SILVA, S. L. da. Roteiro para revisão bibliográfica sistemática: aplicação no desenvolvimento de produtos e gerenciamento de projetos. In: $8^{\circ}$ Congresso Brasileiro de Gestão e Desenvolvimento de Produto - CBGDP, 2011, Porto Alegre. Anais... Porto Alegre, 2011. 12p.

COSTA, P. Z. R. da.; BIZ, P. Cultivando materiais: o uso da celulose bacteriana no design de produtos. In: 30 Simpósio de Pós-Graduação Em Design da Esdi Rio, 2017, Rio de Janeiro.Anais..., Rio de Janeiro, 2017.13p. DAMSIN, B. Bacterial cellulose. New biocomposites based on bacterial cellulose for architectural membrane applications. 2019, 141p. Dissertação Université Libre de Bruxelles. Bruxelas, 2019.

DERME, T.; MITTERBERGER, D.; DI TANNA, U. Growth based fabrication techniques for bacterial cellulose. In: ACADIA 2016: Posthuman Frontiers: Data, Designers, and Cognitive Machines - Proceedings of the 36th Annual Conference of the Association for Computer Aided Design in Architecture, 2016, Ann Arbor. Anais... Ann Arbor, 2016. p. 488-495.

DOMSKIENE, J.; SEDERAVICIUTE, F.; SIMONAITYTE, J. Kombucha bacterial cellulose for sustainable fashion. International Journal of Clothing Science and Technology, v. 31, n. 5, p. 644-652, 2019.

FILLAT, A.; MARTÍNEZ, J.; VALLS, C.; et al. Bacterial cellulose for increasing barrier properties of paper products. Cellulose, v. 25, n. 10, p. 6093-6105, 2018.

GARCÍA, C.; PRIETO, M. A. Bacterial cellulose as a potential bioleather substitute for the footwear industry. Microbial Biotechnology, v. 12, n. 4, p. 582-585, 2019. HARMON, J.; FAIRBOURN, L.; THIBAULT, N. Exploring the Potential of Bacterial Cellulose for Use in Apparel. Journal of Textile Science \& Fashion Technology, v. 5, n. 2, p. 1-9, 2020.

HUANG, Y.; ZHU, C.; YANG, J.; et al. Recent advances in bacterial cellulose. Cellulose, v. 21, n. 1, p. 1-30, 2014.

HÜLSEN, J. Xylium Stool. 2011. Disponível em: <http:// www.jannishuelsen.com/?/work/xyliumstool/>. Acesso em: 02 jan 2021.

INPI - Instituto Nacional da Propriedade Industrial. Ferramenta de busca de patentes. Disponível em $<$ https://www.gov.br/inpi/pt-br>. Acesso em 07 jan. 2021. KAMINSSI, K.; JAROSZ, M.; GRUDZIEŃ, J.; et al. Hydrogel bacterial cellulose: a path to improved materials for new ecofriendly textiles. Cellulose, v. 27, n. 9, p. 53535365, 2020.

KARANA, E.; BLAUWHOFF, D.; HULTINK, E. J.; CAMERE, $S$. When the material grows: A case study on designing (with) myceliumbased materials. International Journal of Design, v. 12, n. 2, p. 119-136, 2018.

LATIPAT. Ferramenta de busca de patentes. Disponível em: < https://lp.espacenet.com/?locale=pt_LP >. Acesso em 07 jan. 2021.

LEGNANI, C.; BARUD, H. S.; CAIUT, J. M. A.; et al. Transparent bacterial cellulose nanocomposites used as substrate for organic lightemitting diodes. Journal of Materials Science: Materials in Electronics, v. 30, n. 18, p. 16718-16723, 2019.

LIVING COLOUR. Biodesign research project. 2017. Disponível em: <https://livingcolour.eu/> Acesso em: 24 set 2020.

MIHALEVA, G. Bio matter in creative practices for fashion and design. Al and Society, Springer London, n. $0123456789,2020$.

MODERN SYNTHESIS. Microbial Weaving. 2020. Disponível em: <https://modernsynthesis.com/microbial-weaving/> Acesso em: 02 jan 2021.

NG, A. Grown microbial 3D fiber art, ava: Fusion of traditional art with technology.In: Proceedings International Symposium on Wearable Computers, ISWC, 2017, Maui. Anais... Maui, 2017 v. Part F130534, p. 209-214.

NG, F. M. C.; WANG, P. W. Natural Self-grown Fashion From Bacterial Cellulose: A Paradigm Shift Design Approach In Fashion Creation. Design Journal, v. 19, n. 6, p. 837-855, 2016.

NG, M. C. F.; WANG, W. A Study of the Receptivity to Bacterial Cellulosic Pellicle for Fashion. Research Journal of Textile and Apparel, v. 19, n. 4, p. 65-69, 2015. 
NIYAZBEKOVA,Z.T.;NAGMETOVA, G.Z.;KURMANBAYEV, A. A. An Overview of Bacterial Cellulose Applications. Biotechnology. Theory and practice, p.1-16, 2018. RAHMAN, M. M.; NETRAVALI, A. N. Aligned Bacterial Cellulose Arrays as "green" Nanofibers for Composite Materials. ACS Macro Letters, v. 5, n. 9, p. 1070-1074, 2016.

RATHINAMOORTHY, R.; KIRUBA, T. Bacterial cellulose-A potential material for sustainable ecofriendly fashion products. Journal of Natural Fibers, v. 00, n. 00, p. 1-13, 2020.

SMITH, R. S. H.; BADER, C.; SHARMA, S.; et al. Hybrid Living Materials: Digital Design and Fabrication of 3D Multimaterial Structures with Programmable Biohybrid Surfaces. Advanced Functional Materials, v. 30, n. 7, p. 1-14, 2020.

STROBEL do NASCIMENTO, Elisa; HEEMANN, A.Perspectivas em design e materiais vivos: discussão da literatura. In: Gampi + Plural Design 2020, 2020, Joinville. Anais Gampi + Plural Design 2020. Anais... Joinville: Editora Univille, 2020. p. 240-253.

STROBEL, E.; LAU, G. M.; ISHIY, F. C.; HEEMANN, A. Design e materiais vivos: perspectivas e aplicações da celulose bacteriana no design industrial, arquitetura e moda. In: Anais [do] ENSUS 2021 - IX Encontro de Sustentabilidade em Projeto. 2021, Florianópolis. Anais... Florianópolis, 2021. v. 9. p. 19-30.

SHUNK, G. K.; GOMEZ, X. R.; AVERESCH, N. J. H. A SelfReplicating RadiationShield for Human DeepSpace Exploration: Radiotrophic Fungi can Attenuate Ionizing Radiation aboard the International Space Station. bioRxiv, p. 205534, 2020.

TED. Suzanne Lee: Cultive suas próprias roupas. 2011. Disponível em: <https://www.youtube.com/watch?v=3p3vl9VFYU>. Acesso em: 02 jan 2021.

URAKI, Y.; NEMOTO, J.; OTSUKA, H.; et al. Honeycomblike architecture produced by living bacteria, Gluconacetobacter xylinus. Carbohydrate Polymers, v. 69, n. 1, p. 1-6, 2007

USPTO - United States Patent and Thendmark. Ferramenta de busca de patentes. Disponível em: < https://www.uspto.gov/ >. Acesso em 07 jan. 2020.

VELÁSQUEZ-RIAÑO, M.; BOJACÁ, V. Production of bacterial cellulose from alternative low-cost substrates. Cellulose, v. 24, n. 7, p. 2677-2698, 2017.

WOOD, J. Bioinspiration in Fashion-A Review. Biomimetics, v. 4, n. 1, p. 16, 2019.

YIM, S. M.; SONG, J. E.; KIM, H. R. Production and characterization of bacterial cellulose fabrics by nitrogen sources of tea and carbon sources of sugar. Process Biochemistry, v. 59, p. 26-36, 2017.

ZOLOTOVSKY, K. BioConstructs - Methods for Bio-Inspired and Bio-Fabricated Design. 2012, 72p. Dissertação - Master of Science in Architecture Studies at the Massachusetts Institute of Technology. Cambridge, 2012.

ZOLOTOVSKY, K.; GAZIT, M.; ORTIZ, C. Guided Growth of Bacterial Cellulose Biofilms. In: 7th International Conference on Biomimetic and Biohybrid Systems, Living Machines (LM), 2018, Paris. Anais... Paris, 2018. p.538-548. 


\section{AUTORES}

ORCID: https://orcid.org/0000-0002-2989-3274

ELISA STROBEL DO NASCIMENTO, M.Sc. | UFPR - Universidade Federal do Paraná - PPGDesign, Curitiba, PR, Brasil | Correspondência para: R. General Carneiro, 460, $8^{\circ}$ andar, sala 814 - Centro, Curitiba - PR, 80060-150| email: elisastrobel@ufpr.br

ORCID: https://orcid.org/0000-0002-4253-3038

GISLAINE MARIA LAU | UFPR - Universidade Federal do Paraná - Design de Produto, Curitiba, PR, Brasil | Correspondência para: R. Nossa Senhora do Monte Claro, 2505 - Colônia Revier - Campo Largo - PR, 83609241 |

email: gislainemlau@gmail.com

ORCID: https://orcid.org/0000-0002-5057-4999

FELIPE DE CARVALHO ISHIY | UFPR - Universidade Federal do Paraná - Design de Produto, Curitiba, PR, Brasil |Correspondência para: R. Florival Elvídio da Silva, 81 Sítio Cercado, Curitiba - PR, 81910-590 | email: ishiy06@ gmail.com

ORCID: https://orcid.org/0000-0002-7029-4505

ADRIANO HEEMANN, Dr. | UFPR - Universidade Federal do Paraná - PPGDesign, Curitiba, PR, Brasil | Correspondência para: R. General Carneiro, 460, $8^{\circ}$ andar, sala 801 - Centro, Curitiba - PR, 80060-150 | email: adriano.heemann@ufpr.br

\section{COMO CITAR ESTE ARTIGO}

NASCIMENTO, Elisa Strobel do; LAU, Gislaine Maria; ISHIY, Felipe de Carvalho; HEEMANN, Adriano. Materiais Vivos, O Caso Da Celulose Bacteriana: Revisão Bibliográfica Da Aplicação No Design Industrial, Arquitetura E Moda. MIX Sustentável, [S.I.], v. 7, n. 4, p. 71-82, set. 2021. ISSN 24473073. Disponível em:<http://www.nexos.ufsc.br/index.php/ mixsustentavel>. Acesso em: dia mês. ano. doi:https:// doi.org/10.29183/2447-3073.MIX2021.v7.n4.71-82. 
